Estudios Constitucionales, Año 10, № 2, 2012, pp. 193 - 230.

ISSN 0718-0195

Centro de Estudios Constitucionales de Chile Universidad de Talca

"Impacto del bloque de constitucionalidad en la interpretación del derecho común.

La interpretación amplia de los abortos permitidos en Argentina"

Laura Clérico - Liliana Ronconi

\title{
IMPACTO DEL BLOQUE DE CONSTITUCIONALIDAD EN LA INTERPRETACIÓN DEL DERECHO COMÚN. LA INTERPRETACIÓN AMPLIA DE LOS ABORTOS PERMITIDOS EN ARGENTINA
}

\author{
IMPACT OF THE BLOCK OF CONSTITUTIONALITY IN THE \\ INTERPRETATION OF THE COMMON LAW. THE BROAD INTERPRETATION \\ OF THE ABORTIONS ALLOWED IN ARGENTINA
}

LAura Clérico*

Profesora de Derecho Constitucional en la Universidad de Buenos Aires

lauraclerico@yahoo.com

LiLIANA RONCONI**

Investigadora adscripta del Instituto Gioja, Facultad de Derecho-UBA

Imronconi@googlemail.com

RESUMEN: La despenalización y legalización del aborto ha encontrado en Argentina nuevos impulsos para su discusión, impulsos al que se le suma un reciente fallo de la Corte Suprema de Justicia de la Nación en el que se resolvió que la normativa local (art. 76 inc. $2^{\circ}$ del Código Penal) debe ser interpretada en forma amplia permitiendo el aborto en casos de violación. En este trabajo nos proponemos estudiar como el máximo órgano de justicia de nuestro país plantea la cuestión del caso y como lo resuelve a la luz de normas del bloque de constitucionalidad, ofreciendo razones de peso constitucional y convencional para imponer una interpretación amplia del derecho local. Asimismo, analizaremos los alcances de las acciones que, conforme lo ordenado por la Corte Suprema, deben Ilevan a cabo los Estados (federal y provinciales) para no sólo dejar de obstaculizar los abortos no punibles sino también para garantizar condiciones médicas y sanitarias para que las mujeres puedan interrumpir su embarazo en condiciones seguras. Por último, nos detendremos en analizar las implicancias que las reglas que la Corte Suprema de Justicia ha establecido para interpretar otros casos de abortos.

ABSTRACT: The debate about decriminalization and legalization of abortion in Argentina has found new impetus for discussion with recent decision of the Supreme Court in which in a new interpretation of the Penal Code (art. 76.2) allows abortion in rape cases. In this paper we propose

\footnotetext{
* Doctora en Derecho por la Universidad de Kiel. Investigadora del Conicet. Artículo presentado el 4 de mayo de 2012 y aprobado el 6 de junio de 2012.

" Becaria de Doctorado de la Universidad de Buenos Aires. Auxiliar Docente de Derecho Constitucional. UBA.
} 
to analyze how the Supreme Court found a solution through applying constitutional principles and international law. Moreover, we will analyze the possible applications of the decision in the provinces to guarantee the access of the abortion for all women (medical and sanitary conditions). At the end, we would like to think about the further implications of the rules that the Court established for future cases of abortion.

PalabRas Clave: Constitución - Derecho federal - Derecho Común - Abortos permitidos - Interpretación amplia.

KEY WORDS: Constitution - Federal Law - Local Law - Legal Abortions - Interpretation.

\section{INTRODUCCIÓN}

La despenalización y legalización del aborto ha encontrado actualmente nuevos impulsos para su discusión. ${ }^{1}$ Estas discusiones se llevan a cabo tanto en el Congreso de la Nación como en distintos medios de comunicación, partidos políticos, organizaciones no gubernamentales, encuentros de movimientos de base y en las Universidades Públicas, entre otros ámbitos. Ahora se suma el de la Corte Suprema de Justicia de la Nación a través de la sentencia recientemente pronunciada en el caso F.A.L. ${ }^{2}$ En estos ámbitos, la idea de la despenalización y legalización del aborto encuentra miradas encontradas. El eje de esta discusión surge ante un conflicto de derechos entre el derecho a la existencia intrauterina del feto y el derecho a decidir de las mujeres. ${ }^{3}$

\footnotetext{
${ }^{1}$ De acuerdo con algunos estudios provenientes de la Ciencia Política, la discusión sobre el aborto forma parte de una agenda para América Latina, v. Pecheny y de la Dehesa 2010, pp. 11-62.

${ }^{2}$ Corte Suprema de Justicia argentina (en adelante CSJN), sentencia "F., A. L. s/ medida autosatisfactiva" del 13 de marzo de 2012 (disponible en: www.csjn.gov.ar).

${ }^{3}$ Los derechos de las mujeres encuentran amplio reconocimiento en el bloque de constitucionalidad: Derecho a la autonomía (art. 19 CN; 11.2 de la CADH; 17 PIDCyP), derecho a la vida y a la integridad física y psíquica (arts. 4, 6 y 7 CADH); derecho a la salud (art. 12 del PIDESC); derecho a la planificación familiar (arts. 10. h) y 12.1 de la Convención sobre la Eliminación de toda Forma de Discriminación contra la Mujer) como asimismo en el bloque federal (Convención Interamericana para Prevenir Sancionar y Erradicar la Violencia Contra la Mujer "Convención De Belém Do Pará", entre otras). En lo que respecta a esta temática en particular varios informes y observaciones de organismos de protección internacional de los derechos humanos enfatizan la importancia de garantizar el derecho a la salud sexual y reproductiva de mujeres y niñas; por ejemplo, la Comisión Interamericana de Derechos Humanos sostiene que "la capacidad de la mujer de controlar su fecundidad tiene una relación fundamental con su capacidad de gozar de un conjunto de derechos básicos; más específicamente, de proteger su integridad física y planificar su vida familiar con su pareja”. CIDH informe sobre Guatemala 2001, OEA/Ser.//V/II.111, doc. 21 rev, de 6 de abril de 2001, párrs. 34. Asimismo, v. CIDH, Informe No 20/07, Solución Amistosa, Petición 161-02, Paulina del Carmen Ramírez Jacinto, México, 9/3/2007, sobre el caso de una niña violada que quedó embarazada y que se le negaba la interrupción del embarazo aunque la ley autorizaba la práctica del aborto para esos casos. En general, véase Comité
} 


\section{II. “Todo Pasa y tOdo Llega...”: LA ACTITUd EVASIVA DE LA CORTE HASTA EL CASO F.A.L.}

En lo que respecta a las discusiones del aborto en el ámbito de la Corte, pareciera que trató de evitarla hasta el caso F.A.L. Con anterioridad se había acercado al tema sin haber sentado una línea jurisprudencial convincente. El derecho a la salud de las mujeres en su faz de derecho a la salud (reproductiva) se diluye, se invisibiliza, en el caso "Portal de Belén". ${ }^{4}$ En este caso, la Corte, por mayoría, ordenó prohibir la producción, distribución y venta de la llamada píldora del día después, INMEDIAT, porque uno de los posibles efectos de ingerirla podría tener "carácter abortivo". ${ }^{5}$ Fallos como éste merecieron una fuerte crítica; ${ }^{6}$ porque para analizar los efectos del referido medicamento el tribunal cita fuentes "científicas" parciales, desactualizadas y no considera, por ejemplo, los informes de la OMS. Además no tiene en cuenta los derechos a la salud reproductiva y a la autonomía de las mujeres. Por el contrario, en el caso "T. S." , que si bien no trata directamente la despenalización del aborto, se puede vislumbrar el planteo del problema como un conflicto de derechos. En esta causa la Corte resolvió por mayoría que la inducción del parto a una mujer en estado de embarazo de un feto anencefálico estaba permitida en atención al derecho a la salud de la madre (integridad psíquica), frente al estado irreversible que excluye la viabilidad extrauterina del feto. De la doctrina de este fallo surge que el derecho a la continuación de la existencia intrauterina del feto puede colisionar con el derecho a la salud de las mujeres, entendida esta última no sólo como salud física sino también psíquica.

Por lo demás, no se volvió a pronunciar sobre el fondo del asunto hasta el caso F.A.L., aunque sí sobre cuestiones formales en dos casos referidos a derechos

para la Eliminación de la Discriminación contra la Mujer, 20º período de sesiones (02/02/1999), Recomendación general No $24 \mathrm{~s} / \mathrm{el}$ art. 12 de la Convención sobre la eliminación de todas las formas de discriminación contra la mujer.

4 "Asoc. Civil Portal de Belén c. Ministerio de Salud y Acción Social”, CSJN-05/03/2002 (disponible en: www.csjn.gov.ar).

${ }^{5}$ La sentencia no tuvo, sin embargo, efectos prácticos directos sobre la distribución de ese medicamento, ya que se refería sólo al fármaco IMEDIAT que para ese entonces se encontraba fuera del comercio.

${ }^{6} \mathrm{~V}$, por ejemplo, Rodríguez (2007), p. 305.

7 “T., S. c. Gobierno de la Ciudad de Buenos Aires”, CSJN, 11/01/2001, voto de los jueces Moliné O’Connor, Fayt, Belluscio, López; Bossert coincidió con la mayoría pero por sus fundamentos. Votaron en disidencia los jueces Barra y Boggiano, (disponible en: www.csjn.gov.ar). 
de salud reproductiva de las mujeres. En el caso "Mujeres por la Vida" Suprema decidió que una asociación civil de la Provincia de Córdoba estaba legitimada activamente (art. 43 de la Const. Nac.) para solicitar que suspendieran la aplicación del programa de salud sexual y reproductiva implementado por el gobierno nacional en todo el país (Ley No 25.673), porque consideraba que dicha norma era violatoria de los "derechos de incidencia colectiva a la vida, a la salud y a la patria potestad". Por su parte la jueza Argibay votó en disidencia -denegando la legitimación-. Sostuvo que si bien estos "son derechos relacionados con los intereses más elevados de las personas, (...) eso no los transforma en colectivos, pues son perfectamente divisibles y ejercidos de diferente manera por cada titular, por cada ser humano". Si bien, ninguno de los miembros de la Corte se pronunció sobre el fondo del asunto, ${ }^{9}$ la jueza Argibay en su voto disidente sostuvo, con fundamento en el principio de autonomía (art. 19 de la Const. Nac.), que fijar "una determinada versión del derecho a la salud y de la vida sexual se transformaría en una imposición colectiva sobre las decisiones individuales".

Posteriormente la Corte resolvió el caso "Yapura"10 sobre un amparo iniciado por una mujer que solicitaba autorización para que se le practicara una ligadura de trompas ${ }^{11}$, luego del parto de su cuarto hijo, por encontrarse en una situación de pobreza extrema. ${ }^{12}$ La justicia provincial entendió que el amparo no era la vía adecuada. ${ }^{13} \mathrm{El}$ caso llegó por apelación extraordinaria a

8 "Mujeres por la vida c. Ministerio de Salud y Acción Social", CSJN, 31/10/2006, (disponible en: www. csjn.gov.ar).

9 Clérico (2009).

10 "Y.G.C. c. Nuevo Hospital El Milagro y otra", CSJN, 06/06/2006 (disponible en: www.csjn.gov.ar).

${ }^{11}$ El 28 de 2006, el Congreso de la Nación aprobó la Ley No 26.130 (2006), que regula el régimen de las intervenciones de contracepción quirúrgica y, entre otras cosas, autoriza expresamente la prácticas denominadas 'ligadura de trompas de falopio' y 'ligadura de conductos deferentes o vasectomía' en los servicio del sistema de salud " (art. 1); v. Siverino Bavio (2006), v., asimismo, referencia al Informe de la nota No 44.

${ }^{12}$ Tanto ella como su cónyuge estaba desocupados y el único sostén económico era el monto que recibían del "Plan Jefas y Jefes de Hogar".

13 Yapura, para justificar su petición, demostró que las autoridades de la clínica (Nuevo Hospital el Milagro situado en la Provincia de Salta) donde iba a tener lugar el parto, ante situaciones similares, se habían negado a realizar la ligadura de trompas sin la "debida autorización judicial". La justicia provincial denegó el pedido por cuestiones formales (ciertas pruebas habían sido presentadas fuera de los plazos legales previstos para hacerlo) y lo rechazó liminarmente porque sostuvo que no debía presentarlo por medio de un amparo. 
la Corte, quien dejó sin efecto la sentencia, alegando que cuando está en juego el derecho a la vida, a la libre determinación y a la intimidad, el amparo era la vía idónea para tratar este tipo de cuestiones. ${ }^{14}$ La Corte se pronuncia así sobre la admisibilidad de la acción de amparo y devuelve el caso para que el tribunal local emita sentencia sobre el fondo del asunto. Al respecto, no deja de asombrar que la Corte no se haya pronunciado sobre el fondo. Como lo demuestra en el caso T.S. y recientemente en F.A.L., la Corte tiene jurisprudencia de sobra para justificar que se puede pronunciar sobre el fondo, más aún en este caso, en el que la ligadura de trompas se debía realizar inmediatamente luego del parto.

Por último, la Corte vuelve a pronunciarse tangencialmente sobre el tema aborto en el caso "Núñez de Zannetti c. Famyl"15. Se trata de un amparo iniciado por una mujer que sufría una resección de intestino con carácter crónico. Esto restringía severamente sus posibilidades alimenticias y la sometía a la llamada nutrición parenteral. La extirpación obedeció a un cuadro de peritonitis grave. "Famyl S.A.", la prepaga, afirmaba que la dolencia era consecuencia de una "maniobra abortiva", practicada en forma clandestina $\mathrm{o}$, al menos, en un lugar inapropiado, no previsto contractualmente, y con la intervención de médicos no adheridos al plan de salud. Invocaba la exclusión de la cobertura y la inexistencia de un acto ilegítimo o arbitrario de su parte, ya que la actora había adherido a un plan cerrado, lo cual implicaba que las prestaciones sanatoriales y médicas debían cumplirse a través de los profesionales y establecimientos que provee la empresa, de modo que se asegure la calidad de la prestación. En este sentido, señalaba que la práctica se habría realizado en un consultorio particular, sin la concurrencia de los recursos humanos y técnicos del caso. La prepaga reconocía que el Estado mediante la sanción de la Ley No 24.754, había trasladado parte de esas cargas a la actividad privada y que la dieta parental forma parte de las prestaciones médicas obligatorias (P.M.O.). Sin embargo, la prepaga no se consideraba deudora de lo que se le reclamaba, ya que sería preciso que esa prestación (la alimentación parenteral) hubiese sido consecuencia de otras prácticas médicas también comprendidas en aquel listado (o sea, también "cubiertas"). Como entiende que esa "segunda condición" no se daba en el caso, entonces, no se consideraba obligada a

\footnotetext{
${ }^{14}$ Voto de los jueces: Petracchi, Highton de Nolasco, Fayt, Maqueda, Lorenzetti y Argibay (en disidencia).

15 “Núñez de Zanetti”, CSJN-9/9/ 2008 (disponible en: www.csjn.gov.ar).
} 
la prestación. La Corte condenó a Famyl a hacerse cargo de la alimentación perinatal. Entendió que la interpretación que proponía la prepaga suponía una restricción al derecho a la salud de la mujer que no surgía ni expresa ni implícitamente del sistema impuesto por la Ley No 24.754 y por la resolución que establece el PMO, ya que el alcance de prestaciones contempladas no hace "acepción de etiologías" (o sea, no remite a la causa de las dolencias) como pretende la prepaga. Por ello, concluye que la posición de la prepaga carecía de fundamentos jurídicos de base legal como convencional, según la interpretación del contrato realizada por los tribunales de grado. Así, la prepaga intentaba desligarse (sin éxito) de su obligación alegando que la usuaria no recurrió a un profesional de la cartilla para atender su dolencia, pero ¿podría haber recurrido a uno de ellos para que se le practicara la interrupción del embarazo que consiguió por otros medios? Muy probablemente habría obtenido una negativa de la prepaga. En este sentido, advertimos en otro lugar, ${ }^{16}$ que la debilidad del argumento de la prepaga, hubiera merecido alguna consideración por parte de la Corte referido a que en estos casos las que se encuentran en una situación de especial vulnerabilidad son las mujeres. En este caso la Corte pudo haberse sumergido de lleno en su fundamentación en los derechos de las mujeres, ya que si bien el caso puede ser interpretado por los resultados como un avance en la defensa de los derechos de las mujeres -que incluso impacta en las relaciones entre particulares-; en su argumentación la Corte parece invisibilizar el lugar de la afectada y con ello pierde otra oportunidad para desarrollar alguna perspectiva expresa de género en su fundamentación.

Hasta aquí tenemos la jurisprudencia zigzagueante de la Corte en materia de salud reproductiva y más precisamente de aborto o interrupción del embarazo. ${ }^{17}$ La situación parece cambiar con el caso F.A.L. del 13 de marzo de 2012 en lo que respecta a la interpretación del alcance de los abortos permitidos en el art. 86 del Código Penal.

A raíz de los fundamentos que surgen de este fallo los pedidos de interrupciones de embarazos fruto de una violación deberían resolverse en forma más rápida y sin necesidad de una decisión judicial. Al respecto sostenemos que el camino argumentativo por el que la Corte sostiene la interpretación amplia de los abortos permitidos (en adelante, tesis de la interpretación amplia), se basa en el

${ }^{16}$ Clérico (2010a).

${ }^{17}$ La duda que surge es: ¿por qué la Corte dejó pasar tantas oportunidades para pronunciarse sobre los derechos de las mujeres respecto de la interrupción de los embarazos y otros temas de salud reproductiva? 
planteo con claridad de los principios constitucionales que se encuentran detrás del art. 86 C.P. Este planteo sumado al realizado por Argibay en su voto permite realizar proyecciones sobre su impacto en las discusiones sobre despenalización del aborto (apartados IV y VII de este trabajo). A su vez, los argumentos que la Corte utiliza para sostener la interpretación amplia del art. 86 inc. $2^{\circ}$ C.P. devienen con claridad del bloque de constitucionalidad, en este punto el fallo presenta una gran riqueza argumentativa para reiterar que la reforma de 1994 requiere replantear los lugares desde los que "tradicionalmente" se pensaron la distribución de competencias entre Estado Nacional (Federal) y provincias, en este caso, respecto de la interpretación del derecho común (apartado VI de este trabajo). Si bien nos detendremos en estos dos puntos, no dejamos de advertir que el fallo sienta otras varias líneas interpretativas que identificaremos pero que no podemos profundizar en esta oportunidad.

Así, para el desarrollo de nuestra lectura de la argumentación del fallo y sus proyecciones sobre la discusión actual sobre el aborto, por un lado, y el federalismo, por el otro lado, identificamos primero los hechos y cuestión del caso, las reglas y argumentos de la Corte que surgen del fallo para luego arribar en los apartados VI y VII a nuestra propuesta de reconstrucción argumentativa.

\section{III. ¿Cómo llega el caso a la Corte? Cuestión del caso: Problema de} INTERPRETACIÓN A LA LUZ DE NORMAS DEL BLOQUE DE CONSTITUCIONALIDAD

El caso llega a la Corte en un contexto de amplia discusión sobre los alcances del art. 86 inc. $2^{\circ}$ del Código Penal. ¿La norma autoriza sólo el aborto del embarazo fruto de una violación que porta una mujer con discapacidad mental (interpretación restringida) o autoriza a abortar a cualquier mujer embarazada cuando dicho embarazo sea fruto de una violación (interpretación amplia)? En este sentido, la interpretación restrictiva de dicho artículo ha limitado el acceso a un aborto por parte de muchas mujeres que han sido violadas. Varios de los casos que llegaron a tener visibilidad mediática hablaban incluso de violaciones de niñas. De esta manera, las niñas y mujeres embarazadas "sin discapacidad mental" ante la negativa de un médico de realizar un aborto, se someten a prácticas caseras de aborto con grave riesgo para su salud y vida o continúan con el embarazo pese a la grave angustia que les genera. ${ }^{18}$ En

\footnotetext{
${ }^{18}$ Respecto del embarazo adolescente y su problemática v. MorlachetTi (2011). Estadísticas sobre aborto clandestino, pueden encontrarse, en: Mario S./ Pantelides E. "Estimación de la magnitud del
} 
algunos casos judicializan su situación y aún así, por lo general, estas mujeres son ignoradas en su pedido ante la justicia. ${ }^{19}$ Las voces de las mujeres son silenciadas o invisibilizadas, por lo menos, de dos maneras: a) se dicta una sentencia judicial denegando el derecho a practicarse un aborto en estos casos, alegando el derecho a la vida de la persona por nacer; b) en otros, la práctica es mucho más perversa: la imposición de realizar un reclamo judicial conlleva en muchos casos la negativa del derecho por el mero paso del tiempo y el avance del embarazo. La práctica del aborto sin riesgo para la vida de las mujeres puede realizarse hasta una cierta etapa del embarazo, y en la mayoría de los casos los tiempos que insume una resolución judicial provoca la expiración de ese plazo, con lo cual, las mujeres quedan imposibilitadas de realizar la práctica sin riesgo para su vida.

En el ámbito legislativo se encuentran en discusión diversos proyectos de ley sobre la despenalización del aborto. ${ }^{20} \mathrm{~A}$ su vez, el pronunciamiento de la Corte en el caso F.A.L. coincidió por horas con la presentación por parte de la Campaña Nacional por el Derecho al Aborto legal, Seguro y Gratuito de un proyecto de ley de "Interrupción Voluntaria del Embarazo: Régimen. Modificación del Código Penal”. ${ }^{21}$

\section{III.1. Los hechos del caso y el "derrotero judicial"}

Se trataba del pedido de autorización para practicar un aborto a una niña de 15 años, A.F., que se encontraba embarazada de ocho semanas como consecuencia de una violación llevada a cabo por su padrastro (pareja de la madre y padre de los hermanos de la niña). El pedido de autorización fue

aborto inducido en Argentina" en: Nota de población No 87, Cepal, 2009, disponible en http://www. eclac.cl/publicaciones/xml/1/36501/lcg2405-P_4.pdf

${ }_{19}$ V. por ejemplo notas del diario Página 12: "Una intervención ante las demoras" del 31 de enero del 2009, "Un derecho con jurisdicción" del 7 de febrero de 2009, "Un derecho que llegó con demoras" del 10 de abril del 2010, "La sentencia que hizo justicia por Ana María" del 12 de mayo del 2010. En muchos casos, ni siquiera con la orden judicial estas mujeres pudieron acceder al aborto de una manera rápida. V. por ejemplo nota diario Página 12 "Ni con el aval del tribunal máximo" del 22 de septiembre del 2007. En muchos de los casos las mujeres violadas son, y pese a todo fueron obligadas a llevar un embarazo a término, con el argumento de que esos casos no entrarían en lo previsto en el art. 86 del Código Penal.

${ }^{20}$ Pueden consultarse en http://www.despenalizacion.org.ar/legislacion_proyParlamentarios.html

${ }^{21}$ Trámite Parlamentario 013 (20/03/2012) No de Expediente 1218-D-2012 (Cámara de Diputados de la Nación), apoyados por varios/as legisladores/as, http://www.abortolegal.com.ar/?p=1816 
oportunamente realizado ante el Ministerio Fiscal de la Provincia de Chubut por la madre de la niña. Madre e hija debieron afrontar un "largo derrotero judicial" 22 y administrativo a la hora de obtener una respuesta a su solicitud: en primer lugar, en el ámbito administrativo, la negativa del médico o del efector de salud correspondiente. En el ámbito judicial inicialmente el juez del fuero penal donde se presenta el pedido se declara incompetente, luego la justicia de familia rechaza el pedido tanto en primera como en segunda instancia, esto a pesar de que existían informes del Equipo Técnico Interdisciplinario donde constaba que la niña "presentaba sintomas depresivos... (e) ideas suicidas persistentes..." por lo que se estimó que "la continuidad de este embarazo contra la voluntad de [la niña] implica [ba] grave riesgo para su integridad psicofísica, incluido riesgo de vida" (considerando $1^{\circ}$ ). Es así como el caso llega al Superior Tribunal de Justicia de la Provincia de Chubut, que decide hacer lugar al pedido y autorizar la práctica del aborto pues se trataba de un caso de "aborto no punible" conforme el art. 86 inc. $2^{\circ}$ del CP. Asimismo, aclara el tribunal que en estos casos no se requiere autorización judicial para llevar a cabo la práctica. De esta manera, finalmente A.F. puede acceder a la intervención abortiva, luego de casi dos meses de haber realizado la solicitud (la solicitud ante la justica se inicia el 14 de enero, la práctica se lleva a cabo el 11 de marzo del 2010).

Sin embargo, el "derrotero judicial" no termina aquí. El Asesor General Subrogante de la Provincia presenta un recurso extraordinario federal en representación del nacituris, que fue concedido por la "gravedad institucional" que presentaba el caso pese a que la práctica ya se había realizado. En general, se alegaba la violación al derecho a la vida de la persona por nacer con referencia a diversos instrumentos internacionales (conf. considerando o 3 ).

III.2. La cuestión del caso. La necesidad del pronunciamiento a pesar de que el caso devino abstracto pero sólo en lo inmediato: jurisprudencia para casos análogos pues son urgentes

La Corte decide dictar sentencia sobre el fondo pese a que la práctica abortiva ya se había realizado, pues "dada la rapidez con que se produce el desenlace

\footnotetext{
${ }^{22}$ Conforme lo sostuvo la Corte argentina en el considerando No 19 del fallo F.A.L (disponible en: www. csjn.gov.ar).
} 
de... [estas] situaciones, es harto difícil que, en la práctica, lleguen a estudio del Tribunal las importantes cuestiones constitucionales que éstas conllevan sin haberse vuelto abstractas. De ahí que, para remediar esta situación frustratoria del rol que debe poseer todo Tribunal..., corresponde establecer que resultan justiciables aquellos casos susceptibles de repetición, pero que escaparían a su revisión por circunstancias análogas a las antes mencionadas". ${ }^{23}$ Por ello, coincidimos con la Corte cuando sostiene que es necesario el pronunciamiento a fin de que sea "conocido para la solución de casos análogos que pueden presentarse en el futuro".

Respecto del problema o cuestión que plantea el caso, la Corte lo encuadra como un problema de interpretación de normas de derecho federal (derecho internacional de los derechos humanos) realizada por el Superior Tribunal de la causa (el de la provincia de Chubut) que lo lleva a realizar una interpretación amplia de los abortos permitidos del inciso $2^{\circ}$ del art. 86 del Código Penal. Esta interpretación del derecho federal es atacada por el Asesor General Subrogante provincial. Por lo cual, no sería acertado concluir que la Corte está entendiendo en el recurso por la simple interpretación de una norma de derecho nacional común, sino por la interpretación de los derechos que sustentan (o no) la norma del art. 86 inc. $2^{\circ}$ del Código Penal. Asimismo, la Corte interpreta que tiene la obligación de sentar jurisprudencia a partir del caso: en palabras de la Corte "se ve obligada a tener que establecer la inteligencia de las previsiones". Esa obligación emanaría del derecho internacional de los derechos humanos, ya que el estado argentino fue advertido en varios informes de organismos de protección internacional por la práctica continua de interpretación restrictiva del alcance del art. 86 inc. 2 del Código Penal. Por eso para la Corte la cuestión no es evaluar sólo la corrección o no de las normas del derecho internacional de los derechos humanos y del art. 75 inc. 23 de la Const. Nac. alegada por el Asesor General provincial sobre el derecho a la continuación de la existencia intrauterina. La cuestión requiere considerar además los derechos de las mujeres en estado de embarazo por haber sido "objeto" de violencia sexual y por las restricciones que sufren a sus derechos cuando se les obstaculizan los pedidos de aborto. ${ }^{24}$

${ }^{23}$ Caso "F.A.L.", consid. 5) con citas de Fallos 310:819; 324:5, 4061 y "Roe v. Wade" (410 U.S. 1131973).

${ }^{24}$ Id. considerandos 7), 8), 15). 


\section{LA REGLA DEL CASO F.A.L. LA TESIS DE LA INTERPRETACIÓN AMPLIA}

La respuesta a la consideración de todos los derechos en juego lleva a la Corte a sostener la interpretación amplia del art. 86 inc. $2^{\circ}$ C.P. Del fallo es posible extraer la siguiente regla que dividimos en dos para su mejor comprensión:

(a) Los estados nacional, provincial o municipales a cargo de los servicios sanitarios tienen la obligación de practicar el aborto cuando se trata de una solicitud proveniente de una mujer en estado de embarazo por violencia sexual, sin ser necesario el pedido judicial de la autorización para practicar la interrupción ni la denuncia judicial de la violación bastando con la mera manifestación de la mujer sobre este hecho ante el médico tratante. ${ }^{25}$

(b) Los estados nacional, provincial o municipales a cargo de los servicios sanitarios tienen la obligación de poner a disposición de las mujeres que solicitan la práctica las condiciones médicas e higiénicas necesarias para llevarla a cabo de manera rápida, accesible y segura. ${ }^{26}$

\section{LOS ARGUMENTOS QUE SUSTENTAN LA REGLA Y SUS PROYECCIONES}

La Corte enuncia y desarrolla argumentos de peso que justifican la regla que surge del fallo: es decir, la interpretación amplia del art. 86 inc. $2^{\circ}$ del Código

\footnotetext{
${ }^{25}$ Con palabras de la Corte: "20) Que es debido a ello que este Tribunal se ve forzado a tener que recordar, tanto a profesionales de la salud como a los distintos operadores de los diferentes poderes judiciales nacionales o provinciales, que por imperio del artículo 19 in fine de la Constitución $\mathrm{Na}$ cional, que consagra el principio de reserva como complemento de la legalidad penal, ha quedado expresamente dicho por voluntad del constituyente que "ningún habitante de la Nación será obligado a hacer lo que no manda la ley, ni privado de lo que ella no prohíbe”. 21) Que teniendo a la luz aquella manda constitucional es que debe interpretarse la letra del artículo 86, inciso $2^{\circ}$, del Código Penal y por dicha razón, se debe concluir que quien se encuentre en las condiciones allí descriptas, no puede ni debe ser obligada a solicitar una autorización judicial para interrumpir su embarazo, toda vez que la ley no lo manda, como tampoco puede ni debe ser privada del derecho que le asiste a la interrupción del mismo ya que ello, lejos de estar prohibido, está permitido y no resulta punible”. Énfasis agregado.

${ }^{26}$ Nuevamente con palabras de la Corte en F.A.L.: "25) Que cuando el legislador ha despenalizado y en esa medida autorizado la práctica de un aborto, es el Estado, como garante de la administración de la salud pública, el que tiene la obligación, siempre que concurran las circunstancias que habilitan un aborto no punible, de poner a disposición, de quien solicita la práctica, las condiciones médicas e higiénicas necesarias para llevarlo a cabo de manera rápida, accesible y segura. Rápida, por cuanto debe tenerse en cuenta que en este tipo de intervenciones médicas cualquier demora puede epilogar en serios riesgos para la vida o la salud de la embarazada. Accesible y segura pues, aun cuando legal en tanto despenalizado, no deben existir obstáculos médico-burocráticos o judiciales para acceder a la mencionada prestación que pongan en riesgo la salud o la propia vida de quien la reclama (ver al respecto, Sesión Especial de la Asamblea General de las Naciones Unidas, desarrollada en junio de 1999)”.
} 
Penal. La mayor parte de esos argumentos son de naturaleza constitucional. A su vez, giran en torno a dos acciones que debe realizar el Estado:

- tiene que cesar de obstaculizar las prácticas de interrupción de embarazos mediante la exigencia de trámites (judiciales y/o administrativos) innecesarios;

- tiene que garantizar una interrupción del embarazo segura actuando en forma suficiente, accesible y rápida.

La Corte advierte así que los estados (nacional y provinciales) tienen obligaciones de respetar como así también de proteger. Veamos.

\section{V.1. El argumento de igualdad de trato y de no discriminación arbitraria}

La médula de la justificación de la Corte está constituida por el argumento de igualdad y de prohibición de toda discriminación respecto de todas las mujeres víctimas de violencia sexual. Sostiene al respecto, que "reducir por vía de interpretación la autorización de la interrupción de los embarazos sólo a los supuestos que sean consecuencia de una violación cometida contra una incapaz mental implicaría establecer una distinción irrazonable de trato respecto de toda otra víctima de análogo delito que se encuentre en igual situación y que, por no responder a ningún criterio válido de diferenciación, no puede ser admitida" ${ }^{27}$ En ambos casos, las mujeres quedaron embarazadas sin haber prestado su voluntad, más aún su autonomía fue violentada por actos (violación) calificados como violencia de género.

En este punto, la Corte se dedica específicamente también a aclarar cuál interpretación debe darse a la norma en cuestión cuando se trata de niñas. De esta manera, aclara que aun cuando la norma no se refiera específicamente a la situación de las niñas, es totalmente aplicable el art. 86 inc. $2^{\circ}$ C.P., ya que "la ley descarta la validez de su consentimiento, y declara que cualquier acceso carnal con ellas es ya una violación (impropia)" ${ }^{28}$ La figura de la violación impropia se encuentra tipificada en el art. 119 del Código Penal. Se trata de casos donde no es válido el consentimiento del acceso carnal ya sea por la discapacidad mental de la persona o porque se trata de una persona menor

\footnotetext{
${ }^{27}$ Considerando 15. Agrega, además, que la sola existencia de una "conjunción disyuntiva" ("o") en el artículo 86 inciso $2^{\circ}$ del Código Penal indica claramente que "no es punible toda interrupción de un embarazo que sea consecuencia de una violación con independencia de la capacidad mental de su víctima" (considerando 18).

${ }^{28}$ Considerando 18.
} 
de edad. En estos casos, no se requiere la violencia, coacción o intimidación para dar por configurada la violación, ya que los sujetos protegidos están impedidos de dar algún tipo de declaración válida. De esta manera, queda impedida toda interpretación que considere que la niña tuvo algún tipo de voluntad en el acto sexual del cual es producto el embarazo. Así, solicitado por su representante legal el pedido de aborto ante el médico, se debe proceder a su realización inmediata sin indagar como se originó el mismo.

V.2. La voluntad del constituyente respecto del art. 75 inc. 23 de la Const. Nac. no fue a favor de una interpretación restrictiva del art. 86 inc. $2^{\circ}$ del Código Penal

Sostiene la Corte que el art. 75 inc. 23 de la Const. Nac. es una cláusula que establece la atribución del Congreso de dictar medidas de seguridad social que protejan a grupos desaventajados, como los niños/niñas - desde el embarazo (de la madre) hasta la finalización del período de enseñanza elemental-, pero esta protección no se logra con medidas punitivas, ${ }^{29}$ sino con medidas de acción positiva, esta fue la finalidad de la norma.

\section{V.3. El argumento del derecho internacional de los derechos humanos}

La Corte aclara que el derecho internacional de los derechos humanos no puede ser utilizado como argumento convincente para sostener la interpretación restrictiva de los supuestos de abortos no punibles, antes bien es un argumento para la tesis de la interpretación amplia del art. 86 inc. $2^{\circ}$. Agregamos más aún $-\mathrm{y}$ en clave de proyecciones de los argumentos de la sentencia-, que el Derecho Internacional de los Derechos Humanos permite la despenalización de otros tipos de aborto. Veamos.

La Corte analiza el art. 4 de la CADH. El inc. 1. del art. 4 de la Convención establece que toda persona tiene derecho a que se respete su vida. Agrega que

\footnotetext{
${ }^{29}$ De esta manera, se refiere en forma muy breve a la ineficiencia del derecho penal en estos casos, esto es como medio para proteger el derecho a la vida del feto. Así deja en claro que "el estado debe cumplir su obligación de protección trabajando en forma preventiva para la protección de la vida. Debe atender a los peligros de la vida en formación que pueden estar originados por el contexto socio-económico general en el que la mujer se sienta desamparada para el caso de que quiera continuar el embarazo y criar a su hijo. Estas obligaciones de protección y realización se cumplen, por ejemplo, a través de un buen sistema de seguridad social; jardines maternales; becas de estudios; entre otros. Estos medios pueden ser eficaces para aquellas mujeres que quieren seguir con su embarazo pero se vean disuadidas de hacerlo por razones sociales y económicas", Clérico (2009).
} 
"este derecho estará protegido por la ley y, en general, a partir del momento de la concepción". Finaliza afirmando que "nadie puede ser privado de la vida arbitrariamente”. A su vez, la Argentina cuando ratificó la Convención sobre los Derechos del Niño declaró (cláusula interpretativa) que el art. 1 debe interpretarse en el sentido que se entiende por niño todo ser humano desde el momento de su concepción y hasta los dieciocho años de edad. Este agregado sobre cómo se interpreta que se comienza a ser niño más el referido inc. 1 del art. 4 han sido utilizados como argumentos para sostener que el Estado argentino no podría despenalizar el aborto. Sin embargo, la Corte concluye que no puede ser utilizado como argumento a favor de restringir los supuestos del art. 86 inc. 20 CP. Cita el Informe 23/81 de la Comisión Interamericana de Derechos Humanos (más conocido como "Baby Boy"), aunque no desarrolla la argumentación que surge de ese documento, tema que realizaremos a continuación. De esta argumentación se puede proyectar, además, que el legislador puede despenalizar otros tipos de abortos, es decir, más allá del art. 86 incisos $1^{\circ}$ y $2^{\circ} \mathrm{CP}^{30}$

En primer lugar, es necesario recordar que la frase "en general" del inciso $1^{\circ}$ del art. 4 de la CADH fue agregada a propuesta de la Com. I. D. H., que advertía que varios Estados americanos permitían el aborto, por ejemplo, en caso de que la vida o salud de la madre estuviesen en peligro o en caso de estupro. El relator encargado de estudiar la propuesta aconsejó, por su parte, suprimir la frase "Y, en general, desde el momento de la concepción", por dos razones. Por un lado para compatibilizar las legislaciones de los Estados que lo permitían; por el otro lado, para evitar algún tipo de conflicto normativo con el art. 6 párr. 1 del Pacto I. D. C. P. que reconoce el derecho a la vida sin el agregado referido. ${ }^{31}$ Sin embargo, fue aprobada la propuesta realizada

\footnotetext{
${ }^{30}$ La argumentación que sigue fue sostenida anteriormente en CLÉRICO (2009).

${ }^{31}$ Comité de Derechos Humanos, Observaciones Finales: Ecuador, 18/08/1998, párr. 11: "El Comité manifiesta su preocupación por el elevado número de suicidios de muchachas jóvenes a que se hace referencia en el informe, que en parte parecen estar relacionados con la prohibición del aborto. A ese respecto, el Comité lamenta que el Estado Parte no haya resuelto los problemas con que se enfrentan a ese respecto las adolescentes, en particular las que han sido víctimas de violaciones, ya que las jóvenes sufren las consecuencias de dichas acciones a lo largo de toda su vida. Estas situaciones, tanto legales como en la práctica son incompatibles con los artículos 3, 6, y 7 del Pacto, así como con el art. 24 cuando hay involucradas jóvenes menores de edad. El Comité recomienda que el Estado Parte adopte todas las medidas legislativas y de otra índole necesarias para ayudar a las mujeres, en particular a las adolescentes, que se enfrentan con el problema de un embarazo no deseado a lograr acceso a servicios apropiados de
} 
por la Com. I. D. H., es decir, con el agregado de la frase „en general“. Esta aprobación fue fruto de largos debates en los que varios Estados del sistema interamericano proponían la supresión de la frase. Por ello, la letra y el contexto histórico de discusión de la norma no conforman un buen argumento para sostener que la obligación del Estado de proteger la vida sólo se cumple a través de adoptar o mantener una penalización absoluta de todo tipo de aborto. Así no puede ser utilizado como un argumento para restringir la interpretación del inciso $2^{\circ} \mathrm{del}$ art. $86 \mathrm{CP}$, sino que, por el contrario, pareciera que habilita al legislador despenalizar otro tipo de abortos.

Por otra parte una interpretación dinámica (sumado el principio pro homine) de la Convención lleva a admitir la despenalización de otros tipos de abortos. En oportunidad de pronunciarse sobre el carácter vinculante de la Declaración Americana de Derechos y Deberes del Hombre, la Com. I. D. H. en "Baby Boy" ${ }^{32}$ interpretó el alcance del art. I de esa Declaración que establece que todo ser humano tiene derecho a la vida. Los peticionantes solicitaban ante la Com. I. D. H. que Estados Unidos fuera condenado por haber practicado a una madre un aborto en violación del referido art. I de la Declaración. Sostenían que esa norma protegía el derecho a la vida desde el

salud y de educación”. Cursiva agregada; Chile, 30/03/1999, párr. 15: “15. La penalización de todo aborto, sin excepción, plantea graves problemas, sobre todo a la luz de informes incontestados según los cuales muchas mujeres se someten a abortos ilegales poniendo en peligro sus vidas. El deber jurídico impuesto sobre el personal de salud de informar de los casos de mujeres que se hayan sometido a abortos puede inhibir a las mujeres que quieran obtener tratamiento médico, poniendo así en peligro sus vidas. El Estado parte está en el deber de adoptar las medidas necesarias para garantizar el derecho a la vida de todas las personas, incluidas las mujeres embarazadas que deciden interrumpir su embarazo. En este sentido: El Comité recomienda que se revise la ley para establecer excepciones de la prohibición general de todo aborto y proteger el carácter confidencial de la información médica". Perú, 15/11/2000, párr. 20: "Es signo de inquietud que el aborto continúe sujeto a sanciones penales, aun cuando el embarazo sea producto de una violación. El aborto clandestino continúa siendo la mayor causa de mortalidad materna en el Perú. El Comité reitera que estas disposiciones son incompatibles con los artículos 3, 6 y 7 del Pacto y recomienda que se revise la ley para establecer excepciones a la prohibición y sanción del aborto," entre otros.

32 En el caso, No 2.141 la Comisión Interamericana de Derechos Humanos aprobó la Resolución 23/81. El caso es más conocido por el nombre de "Baby Boy" referido a los Estados Unidos de Norteamérica. La Comisión concluyó, que la Declaración Americana de Derechos y Deberes del Hombre es derecho vinculante para ese estado. Los Estados Unidos son estados miembro de la OEA, son parte además en la Carta de Bogotá modificada por el Protocolo de Buenos Aires de 1970, en relación con el cual "las disposiciones de otros instrumentos internacionales y resoluciones de la OEA sobre derechos humanos adquieren fuerza obligatoria"; la Declaración fue adoptada con el voto de los Estados Unidos. 
momento de la concepción. Agregaban que el alcance de ese derecho debía entenderse en consonancia con el 4.1 de la Convención Americana aunque los Estados Unidos no era parte de esa Convención. La Com. I. D. H. resolvió por mayoría que ese Estado no había violado el art. I de la Declaración. Para ello se basó en el argumento de la historia de la Declaración y el art. 4.1 de la Convención, que protege la vida desde el momento de la concepción pero en general, admitiendo así que los Estados pueden despenalizar el aborto. Esto implica en el caso sometido a examen que decisiones como "Roe vs. Wade”, ${ }^{33}$ entre otras, no constituyen violación de los artículos I, II, VII y XI de la Declaración Americana de los Derechos y Deberes del Hombre.

La Corte en F.A.L. utiliza también como argumento la interpretación que debe darse a la Convención de los Derechos de los Niños. En este sentido sostiene que (a) no se desprende de dicha convención que el derecho a la vida deba ser protegido desde la concepción, esto es que debe darse una interpretación restrictiva del art. 86 inc. $2^{\circ} \mathrm{CP}^{34}$ (b) Aclara asimismo que "el artículo $2^{\circ}$ de la Ley $N^{o} 23.849$, en cuanto estipula que el artículo $1^{\circ}$ de la Convención "debe interpretarse en el sentido que se entiende por niño todo ser humano desde el momento de la concepción", no constituye una reserva que, en los términos del artículo $2^{\circ}$ de la Convención de Viena sobre el Derecho de los Tratados [sino] una declaración interpretativa". ${ }^{35}$ Ambas interpretaciones (a y b) pueden ser relevantes para la resolución de otros casos de abortos, incluso para sostener la necesidad de su despenalización en todo supuesto.

\footnotetext{
33 “Roe vs. Wade", US 113, 93 (1973). En el caso se sostiene la solución diferenciada que supone que cuanto menor es la etapa de gestación mayor peso adquiere el derecho a la privacidad de la mujer; a la inversa, cuanto más adelantado el embarazo y, en especial, a partir de que es viable, mayor peso adquiere el derecho a la continuación del desarrollo del feto. El caso se originó por el ataque a la constitucionalidad de las leyes de Texas que penalizaban el procurar un aborto excepto cuando fuera por consejo médico con el propósito de salvar la vida de la madre. Esta normativa fue declarada inconstitucional. La Corte sentó pautas para orientar la labor legislativa. La interrupción del embarazo es permisible si se realiza en una etapa de gestación en la que el feto no tiene posibilidad de supervivencia fuera del cuerpo de la madre. Aquí cobra fuerza el argumento de autonomía de la mujer sobre su cuerpo. Sin embargo, a partir de aquella etapa en que el feto adquiere viabilidad, entonces el estado "al promover su interés en la potencialidad de la vida humana, si lo elige, regular y aun prohibir el aborto, excepto cuando éste sea necesario, según el juicio médico, para la preservación de la vida o la salud de la madre". V., además, "Planned Parenthood of Southeastern Pennsylvania v. Casey".

${ }^{34}$ Tanto es así, alega la Corte, que "el Comité de los Derechos del Niño (...) ha manifestado su preocupación por la interpretación restrictiva del artículo 86 del Código Penal” (cons. 13).
}

${ }^{35}$ Considerando 13. 


\section{V.4. El argumento del principio de dignidad de la persona: prohibición de tratar a las mujeres como medios}

El principio de inviolabilidad de las personas marca una esfera de intereses del individuo que no podemos invadir para obtener un beneficio para otros o en aras del bien común. ${ }^{36}$ De esta manera, la Corte reconoce, con cita expresa de Nino, que exigir a una mujer que ha sufrido un ataque en sus derechos más fundamentales que lleve su embarazo a término, implica una carga desproporcionada que es incompatible con el principio de inviolabilidad de las personas. ${ }^{37}$

Lo interesante de este argumento de la "carga desproporcionada" 38 desarrollado por la Corte, es que el mismo configura un valioso aporte para interpretar la normativa del art. 86 en general, como asimismo para sostener la necesidad de despenalizar el aborto en otros supuestos. En efecto, cualquier mujer que no desea su embarazo se ve afectada en su derecho a la inviolabilidad y autonomía. Así, se priva a las mujeres de "algo valioso" (derecho a la autonomía, a la salud, entre otros) que no puede ser invisibilizado a la hora de la discusión de la despenalización de otros tipos de abortos.

\section{V.5. El argumento del examen de estricta legalidad y de la interpretación pro homine. El argumento sistemático}

La interpretación amplia del art. 86 inc. $2^{\circ} \mathrm{CP}$ es la que imponen el principio de estricta legalidad y la interpretación pro homine. ${ }^{39}$ Respecto de este último punto, sostuvo la Corte que se debe "privilegiar la interpretación legal que más derechos acuerde al ser humano frente al poder estatal”. Por otro lado, el principio de estricta legalidad y el principio de última ratio del derecho penal nos dicen que toda medida que implique una pena debe ser interpretada en forma restrictiva, siempre beneficiando la libertad de acción de las personas.

\footnotetext{
36 NinO (1989).

37 Considerando 16.

${ }^{38}$ V., además el apartado sobre conflicto de derechos en este trabajo.

39 Mónica Pinto sostiene que "el principio pro homine es un criterio hermenéutico que informa todo el derecho de los derechos humanos, en virtud del cual se debe acudir a la norma más amplia, o a la interpretación más extensiva, cuando se trata de reconocer derechos protegidos e, inversamente, a la norma o a la interpretación más restringida cuando se trata de establecer restricciones permanentes al ejercicio de los derechos o su suspensión extraordinaria”, PINTO (2004).
} 
La interpretación restringida del art. 86 inc. 20 "amplía sustancialmente el alcance del castigo penal" y, por lo tanto, es contrario a estos principios. Así, la interpretación que se impone es aquella que acuerda mayores garantías a las mujeres embarazadas, producto de una violación ya que la misma normativa (inc. $2^{\circ}$ del art. 86 ) prevé claramente dos supuestos, determinados por la misma norma (conjunción “o”).

\section{V.6. Conclusiones intermedias: la convicción argumentativa} de la interpretación amplia del inciso $2^{\circ}$ del art. 86 del Código Penal sobre la base de "las razones de la máxima jerarquía normativa"

Los argumentos que hemos trabajado (de la igualdad de trato y de no discriminación arbitraria, la voluntad del constituyente, el derecho internacional de los derechos humanos, el principio de dignidad de la persona y el examen de estricta legalidad), confirman en forma convincente la tesis de la interpretación amplia del art. 86 inciso $2^{\circ}$ del Código Penal. Con esto la Corte cumplió su deber de "esclarecer la confusión reinante en lo que respecta a los abortos no punibles y a fin de evitar frustraciones de derecho por parte de quienes peticionen acceder a ellos, de modo tal que se configuren supuestos de responsabilidad internacional".

Sin embargo, la Corte con acierto no detiene su argumentación en este punto. Continúa estableciendo las obligaciones que tienen los Estados (nacional y provinciales) no sólo respecto de no obstaculizar los abortos no punibles sino de garantizar condiciones médicas y sanitarias para que las mujeres puedan interrumpir su embarazo en condiciones seguras. Así pareciera que la Corte reconoce no sólo que el aborto en ciertos casos está permitido sino además que es un derecho de las mujeres acceder al mismo. Veamos esto con más detalle.

\section{LAS OBLIGACIONES ESTATALES}

A la luz de los diferentes instrumentos internacionales de derechos humanos que se refieren al derecho a la salud, y en especial a la salud sexual y reproductiva, podemos afirmar que las obligaciones que tienen los Estados (tanto nacional como provinciales como municipales) giran en torno de las siguientes cuestiones: disponibilidad, accesibilidad, aceptabilidad y calidad en lo que se refiere al acceso al aborto. ${ }^{40}$ Sin embargo, dichas obligaciones no se limitan a

${ }^{40}$ Para mayor amplitud, v. Ramos (2009). 
la cuestión concreta del aborto sino que están presentes antes y después de la práctica. ${ }^{41}$ De esta manera, los Estados están obligados a prestar información y asistencia tanto en lo referente a los derechos que asisten a las mujeres en lo que hace a su salud reproductiva previo a que las mismas se vean ante la situación de un embarazo no deseado como a brindar la adecuada asistencia médica y psicológica después de realizado el aborto.

Algunas de estas obligaciones fueron claramente especificadas por la Corte.

\section{VI.1. Obligación de no obstaculizar los abortos no punibles. La práctica contra legem de la judicialización}

La Corte deja bien en claro que cuando se trate de casos de mujeres violadas, los médicos no deben requerir la autorización judicial para proceder a realizar el aborto, pues estos casos caen dentro de la esfera del art. 86 inc. $2^{\circ}$. C.P. Agrega la Corte que el pedido de autorización judicial es una práctica contra legem, burocrática, innecesaria y carente de sentido, "fomentada por los profesionales de la salud y convalidada... por los operadores judiciales”. Advierte que en estos casos la resolución del problema debe ser decidida por la mujer embarazada y comunicada al médico diplomado, pero no debe ser obstaculizada requiriendo su manifestación ante un magistrado u otra autoridad.

\section{VI.2. Obligación de no obstaculizar solicitando denuncia policial y/o judicial de la violación: basta con la mera manifestación de las mujeres}

La Corte establece cómo se acredita que la situación de embarazo fue producto de una violación. En este sentido, el fallo es muy alentador, ya que se establece que en estos casos el aborto debe practicarse con la sola declaración jurada de las mujeres, víctimas de violación, o de su representante legal en caso de que sea menor de edad, ante el médico en la que manifieste que el embarazo es consecuencia de una violación. ${ }^{42}$

\footnotetext{
${ }^{41}$ Estas obligaciones han sido claramente detalladas en el Informe de la CIDH, Acceso a Servicios de Salud Materna desde una Perspectiva de Derechos Humanos, OEA/Ser.L/V/II. Doc. 69, 7 de junio de 2010.

${ }^{42}$ En este sentido cabe tener en cuenta lo advertido por la Corte IDH en un caso reciente donde estableció que "(...) a la Corte le resulta evidente que la violación sexual es un tipo particular de agresión que, en general, se caracteriza por producirse en ausencia de otras personas más allá de la víctima y el agresor o los agresores. Dada la naturaleza de esta forma de violencia, no se puede esperar la existencia de pruebas gráficas o documentales y, por ello, la declaración de la víctima constituye una prueba fundamental
} 
Quizá esta sea una de las principales críticas que el fallo ha recibido de parte de la doctrina más conservadora, pues postulan que cualquier mujer podría declarar que fue violada y así podría acceder a un aborto. Sin embargo, la crítica del fallo es infundada por al menos, dos cuestiones. ${ }^{43}$ Por un lado, la Corte conoce el diagnóstico: existe una práctica contra legem de obstaculización de los abortos permitidos por el art. $86 \mathrm{CP}{ }^{44}$ la estrategia es conocida: el pedido de autorización judicial, entre otras formas. La Corte conoce el contexto, si antes se pedía la autorización judicial innecesaria para practicar los abortos permitidos, frente a esta nueva interpretación de la Corte, es muy probable que no se solicite más la autorización para el aborto pero sí para acreditar la violación. Nuevamente la judicialización sería la práctica contra legem para obstaculizar el ejercicio de la autonomía de las mujeres. Por el otro lado, la Corte respondió por adelantado a sus críticos. Asume que pueden existir "casos fabricados". Sin

sobre el hecho" (p. 100) y "en relación con el contenido de las declaraciones de la señora Fernández Ortega, la Corte considera que no es inusual que el recuento de hechos de esta naturaleza contenga algunos aspectos que puedan ser considerados, a priori, imprecisiones en el relato. No es la primera vez que un tribunal internacional de derechos humanos debe observar eventuales divergencias en los relatos de personas que se refieren a violaciones sexuales de las cuales habrían sido víctimas" (p. 104). Por último, "de la lectura de las declaraciones mencionadas, la Corte considera que las diferencias en su relato no resultan sustanciales. En ellas se observa que la señora Fernández Ortega utiliza las expresiones "me violaron", o denomina a los hechos como "violación" o "abuso sexual", indistintamente, para referirse a todo el evento lesivo, sin identificar aquellos términos, exclusivamente, con el hecho de la penetración sexual. De allí que en algunas oportunidades ella indique de igual manera que quienes la violaron fueron tres o un militar. Un ejemplo claro de este uso dual del concepto de violación por parte de la señora Fernández Ortega se ve en la ampliación de su declaración ante el Ministerio Público civil de 14 agosto de 2009, en la cual afirmó "los que me violaron son elementos del Ejército mexicano" e inmediatamente, en esa misma declaración, indicó "los vi de cerca, sobre todo el que me violó, porque estuvo encima de mí". De allí que la Corte considera que se trata de un giro o uso del lenguaje más que de una inconsistencia en cuanto a los hechos y que, en realidad, es una discrepancia sólo aparente y no menoscaba la credibilidad de lo declarado" (p. 106). Corte IDH, Caso Fernández Ortega y Otros vs. México, Sentencia de 15 de mayo de 2011.

${ }^{43}$ En este sentido, sostiene Alberto Bianchi: "obviamente la sencillez de este trámite puede generar una "suerte de aborto" pues cualquiera que deseara abortar podría formular falsamente esta declaración...". "Los requisitos para exigirlos además son muy sencillos...". "Obviamente cuando el aborto no lo pida una mujer violada, sino alguien que lo quiere para liberarse de la "servidumbre" de la gestación y conseguir un ascenso en el trabajo...". BIANCHI (2012).

${ }^{44}$ V. el Informe de un grupo de ONG (Cedes, Insgenar, Cladem, Ela, Foro por los Derechos Reproductivos, Católicas por el Derecho a Decidir, Cels, Foco, Feim y ADC) presentado en abril de 2012 ante la ONU que explica las dificultades que padecen las mujeres para acceder a los derechos sexuales y reproductivos y, en especial, a los abortos no punibles aun después del fallo de la Corte en el caso F.A.L.: Comunicación Conjunta para Examen Periódico Universal Argentina, Sesión 14, 2012: "Los derechos sexuales y los derechos reproductivos", (disponible en: http://www.adc.org.ar/sw_contenido.php?id=870). 
embargo, advierte que esto "no puede ser nunca razón suficiente para imponer a las víctimas de delitos sexuales obstáculos que vulneren el goce efectivo de sus legítimos derechos o que se constituyan en riesgos para su salud". ${ }^{45}$

Por otro lado, corresponde decir que no es fácil para una mujer manifestar -sea cual fuere el profesional tratante o la autoridad- el hecho de la violación. Esta manifestación provoca una estigmatización muy fuerte. ${ }^{46} \mathrm{En}$ este sentido, debe tenerse presente lo sostenido por la Corte IDH respecto de que "la violación sexual es una experiencia sumamente traumática que tiene severas consecuencias y causa gran daño físico y psicológico que deja a la víctima "humillada física y emocionalmente", situación difícilmente superable por el paso del tiempo, a diferencia de lo que acontece en otras experiencias traumáticas. De ello se desprende que es inherente a la violación sexual el sufrimiento severo de la víctima, aun cuando no exista evidencia de lesiones o enfermedades físicas. En efecto, no en todos los casos las consecuencias de una violación sexual serán enfermedades o lesiones corporales. Las mujeres víctimas de violación sexual también experimentan severos daños y secuelas psicológicas y aun sociales". ${ }^{47}$ Por todo ello, creer que el hecho de exigir una simple manifestación ante el médico tratante va a llevar a que las mujeres practiquen abortos todos los días es no tomar en serio la autonomía de las personas ni la situación de denigración de la dignidad que representa una violación, considerando no sólo el hecho del acceso carnal en contra de la voluntad sino todo lo que rodea estas situaciones.

Sin embargo, tomar en cuenta la crítica al caso F.A.L. sobre este punto (proveniente de posturas conservadoras) puede resultar interesante. Si consideramos que con la simple declaración una mayor cantidad de mujeres pedirían abortos alegando una supuesta violación debemos asumir también que el Estado está incumpliendo todas sus obligaciones anteriores a la situación de embarazo no deseado, esto es acceso a métodos conceptivos, educación sexual, desarmar prácticas que contienen estereotipos de género y que cristalizan la imagen de la "mujer" como "reproductora", entre otras cosas. Así, una vez más, es necesario repetir que no se le puede trasladar la responsabilidad

\footnotetext{
45 Considerando 28.

${ }^{46} \mathrm{~V}$. Informe de la Comisión IDH Acceso a la Justicia para las mujeres víctimas de violencia en las Américas, OEA/Ser.L/V/II. Doc. 68, 20 enero 2007.

47 Corte Interamericana de Derechos Humanos, "Fernández Ortega vs. México", sentencia del 30 de agosto de 2010, párrafo 124.
} 
por las obligaciones estatales incumplidas a las mujeres sino que los Estados deberían preguntarse sobre el funcionamiento y eficacia de sus acciones que debe generar las condiciones adecuadas para que las mujeres tengan acceso real al ejercicio de sus derechos.

De esta manera, la exigencia de cualquiera de estas dos cuestiones, denuncia policial o resolución judicial, puede ser considerada un acto de violencia institucional que "puede" traer aparejada responsabilidad "penal o de otra índole" para quienes las exigen. En este punto, si bien la Corte habla de que "puede" existir responsabilidad de los funcionarios que de alguna u otra manera impidan o demoren el acceso al aborto sostenemos que esto debería interpretarse como un "debe", esto es, quien impida el acceso al aborto en casos no punibles deberá ser denunciado en sede penal y sometido a proceso conforme lo establezca la legislación pertinente. Además, el Estado (nacional, provincial o municipal) que provea el servicio de salud -y en el que el agente que obstaculizó el aborto mediante pedido de autorización judicial- puede ser demandado judicialmente por los daños y perjuicios que ocasione esta práctica contra legem.

\section{VI.3. Deber de protección a las mujeres víctimas de violencia sexual}

Preocupada por la gravedad y trascendencia social que revisten las situaciones de violencia para las mujeres, la Corte no deja de señalar la necesidad de que tanto en el ámbito nacional como en los provinciales se extremen los recaudos a los efectos de brindar a las víctimas de violencia sexual, en forma inmediata y expeditiva, la asistencia adecuada para resguardar su salud e integridad física, psíquica, sexual y reproductiva. Estas acciones se refieren a distintos aspectos e implican:

- la obligación de los Estados de asegurar a las víctimas un ambiente cómodo y seguro que brinde privacidad y confianza en lo que respecta a la prestación de tratamientos médicos preventivos para reducir riesgos específicos derivados de las violaciones;

- la asistencia psicológica inmediata y prolongada de la víctima; ${ }^{48}$

- la obtención y conservación de pruebas vinculadas con el delito; ${ }^{49}$

48 Corte Interamericana de Derechos Humanos, "Fernández Ortega vs. México", sentencia del 30 de agosto de 2010, párrafo 124.

49 Sostuvo la Corte Interamericana de Derechos Humanos, "Fernández Ortega vs. México", sentencia del 30 de agosto de 2010, que "en una investigación penal por violencia sexual es necesario que: i) la declaración de la víctima se realice en un ambiente cómodo y seguro, que le brinde privacidad y 
- el asesoramiento legal del caso.

Así el deber estatal ante estos casos implica que se proteja a la víctima brindándole atención médica integral, tanto de emergencia como de forma continuada. ${ }^{50}$ Todo esto debe lograrse evitando siempre cualquier tipo de reiteraciones innecesarias que hagan revivir a la víctima aquella situación de vivencia traumática. ${ }^{51}$

\section{VI.4. Obligación de generar condiciones adecuadas para realizar la práctica}

En los casos de aborto no punible, el Estado está obligado a garantizar que la práctica se pueda llevar a cabo de manera rápida, accesible y segura, asegurando las condiciones médicas e higiénicas debidas. En cuando a la rapidez, aclara la Corte, que en estas cuestiones la mínima demora (burocrática) puede implicar la negativa del derecho, al poner en riesgo la vida de la mujer. En muchos casos para asegurar estas condiciones se ha realizado protocolos "de aborto no punible" 52 donde se aclara cuál es el alcance que debe darse a la normativa legal y las condiciones para llevar a cabo la intervención. Sin embargo, esto no ha mejorado en mucho la situación de las mujeres víctimas de violación, pues varios efectores de salud siguieron solicitando la referida autorización judicial

confianza; ii) la declaración de la víctima se registre de forma tal que se evite o limite la necesidad de su repetición; iii) se brinde atención médica, sanitaria y psicológica a la víctima, tanto de emergencia como de forma continuada si así se requiere, mediante un protocolo de atención cuyo objetivo sea reducir las consecuencias de la violación; iv) se realice inmediatamente un examen médico y psicológico completo y detallado por personal idóneo y capacitado, en lo posible del sexo que la víctima indique, ofreciéndole que sea acompañada por alguien de su confianza si así lo desea; v) se documenten y coordinen los actos investigativos y se maneje diligentemente la prueba, tomando muestras suficientes, realizando estudios para determinar la posible autoría del hecho, asegurando otras pruebas como la ropa de la víctima, investigando de forma inmediata el lugar de los hechos y garantizando la correcta cadena de custodia, y vi) se brinde acceso a asistencia jurídica gratuita a la víctima durante todas las etapas del proceso" (párrafo 194).

${ }^{50}$ Respecto de las implicancias del acceso a la información en este tema, v. Informe de la CIDH, Acceso a Servicios de Salud Materna desde una Perspectiva de Derechos Humanos, OEA/Ser.L/V/II. Doc. 69, 7 de junio de 2010, como asimismo CIDH, Acceso a la Información en Materia Reproductiva desde una Perspectiva de Derechos Humanos OEA/Ser.L/V/II. Doc. 6122 noviembre 2011.

${ }^{51}$ Considerando 30.

${ }^{52}$ En el ámbito nacional, tenemos la "Guía Técnica para la Atención Integral de los Abortos no Punibles. Cumplimiento efectivo de los derechos sexuales y reproductivos", Ministerio de Salud, Presidencia de la Nación, octubre del 2007, actualizada en junio del 2010. Estos protocolos existen también en Provincia de Buenos Aires (2007), Ciudad de Buenos Aires (2007), Neuquén (2007). Luego del caso FAL y hasta el momento dos provincias sancionaron estos protocolos: Salta y Córdoba. 
confirmando, como bien lo identifica la Corte, la existencia de una práctica contra legem. Cabe advertir, que sin duda si esto ha ocurrido es porque el estado nacional y los provinciales no han generado los mecanismos de control eficaces para desterrar estas prácticas.

Además, los prestadores deben contar con la infraestructura (de equipos, de material, recursos humanos, entre otros) adecuada para atender estas situaciones en forma urgente. Estas condiciones adecuadas deben responder y estar estructuradas de forma tal que impliquen sobre todo el debido respeto a la autonomía y a la dignidad de las mujeres que padecen un embarazo no deseado. En cuanto a la autonomía de las mujeres los médicos deben limitarse a tomar la declaración de violación y la voluntad de las mujeres de interrumpir el embarazo sin estar permitido a los mismos introducir consideraciones sobre cuestiones éticas o morales en dicha situación. Asimismo, respecto a la dignidad las mujeres no pueden ser sometidas a ningún trato cruel o inhumano (por ejemplo, traslado de la responsabilidad de la violación, reuniones con comité de ética, entre otros.) al solicitar la práctica de interrupción del embarazo.

\section{VI.5. Obligación de garantizar el acceso a los servicios de salud. El caso de la objeción de conciencia}

La práctica contra legem de impedir el acceso a los casos de abortos no punibles nos habla de una imposibilidad de parte de las mujeres de acceder a este derecho por acciones estatales arbitrarias. Mediante esta práctica quienes resultan fuertemente afectadas son aquellas mujeres "pobres" que no tienen posibilidad de acceder al servicio "de otra manera" ("aborto clandestino") y que por distintas causas carecen de acceso a la justicia. Así, se conjugan una multiplicidad de barreras para poder acceder al aborto: legales (judicialización), económicas, de información, entre otras. ${ }^{53}$ Sin embargo, es claro y así lo ha afirmado la Corte en este fallo, que el acceso a los servicios de salud debe ser garantizado en forma real por parte de todos los efectores de salud, públicos o privados.

En este sentido, además de las obligaciones que hemos analizado anteriormente, especial hincapié hace la Corte en el tema de objeción de conciencia. Este es "el derecho a no ser obligado a realizar acciones que contrarían convicciones éticas o religiosas muy profundas del individuo". ${ }^{54}$ Sin embargo en el

${ }^{53}$ Ramos (2009).

${ }^{54}$ Alegre (2009). 
caso F.A.L. la Corte le pone un límite a este derecho al sostener que si bien es posible que el personal sanitario lo ejerza, su ejercicio no puede traducirse en una negativa del derecho de las mujeres a acceder al aborto en las condiciones antes descriptas. ${ }^{55}$

En primer lugar, la objeción de conciencia podrá ser realizada con mayor amplitud en aquellos casos donde el ejercicio de la misma no limite el derecho de las mujeres. Esto es, por ejemplo, cuando se trate de casos donde la mujer pueda ser derivada -sin producir dilaciones indebidas- a otro médico o a otro servicio sanitario, en condiciones de igualdad. En estos casos, el médico objetor debe limitarse a derivar a la paciente, sin que pueda permitirse hacer consideraciones éticas o morales de cualquier tipo. La objeción de conciencia ampara su derecho pero no tolera que se ejerzan influencias sobre las decisiones personales de los demás. En estos casos, entonces, el derecho a ser objetor de conciencia está supeditado a que exista una posibilidad de acceso cierto al derecho a realizar un aborto, de lo contrario esta práctica se traduciría en una negativa del derecho. ${ }^{56}$

Luego tenemos las situaciones donde la derivación no es posible o si lo fuera implicaría un esfuerzo tal para la afectada que se traduciría en una negativa del derecho. Aquí nos estamos refiriendo a casos, nada excepcionales, donde no existe otro centro de salud cercano, o donde no existe otro médico dispuesto a llevar a cabo la práctica (no objetor). En estos casos, el derecho del médico a ser objetor de conciencia tiene que ceder ante el derecho de la mujer a realizarse un aborto ${ }^{57}$ conforme las condiciones ya analizadas (puntos V.1 a V. 4 de este trabajo).

\section{VI.6. La norma del art. 86 inc. $2^{\circ}$ del Código Penal es autoejecutable (operativa). El carácter de ayuda de los Protocolos o reglamentaciones}

Que el derecho al aborto de las mujeres violadas sea operativo implica que las mismas deben acceder a la práctica sin necesidad de que exista una reglamentación en tal sentido. Esto es: la ausencia de una reglamentación (en estos casos se han utilizado los protocolos de atención) no puede ser invocada como

\footnotetext{
55 Estas condiciones fueron analizadas en forma muy clara y detallada por la Corte Constitucional de Colombia en la Sentencia T-209 de febrero del 2008.

56 La derivación deberá estar resuelta con antelación por las entidades médicas o por los profesionales a fin de no vulnerar el derecho de las mujeres a que se realice el aborto en forma urgente.

57 V. Alegre (2009).
} 
excusa por parte del Estado (nacional, provincial o municipal) para dejar de cumplir con el derecho.

De esta manera, si bien la Corte exhorta a las autoridades nacionales y provinciales a implementar y hacer operativos protocolos hospitalarios que brinden información completa a las posibles afectadas y por otro lado que permitan atender estos casos sin dilaciones, esto no puede ser interpretado de manera tal que implique denegación de derechos o restricción de los mismos.

Estos protocolos tienen el carácter de guías pero no son los que habilitan a llevar a cabo la intervención. Por el contrario, esta habilitación está dada por la normativa internacional, nacional y, a partir del fallo F.A.L., por las instrucciones brindadas por la Corte, por lo tanto ningún prestador del servicio de salud podrá excusarse en la ausencia de protocolos para negar el derecho. En caso de que la provincia no sancione el protocolo, las autoridades correspondientes podrán estarse a lo indicado en el protocolo nacional para llevar a cabo la intervención o a las interpretaciones que surgen del fallo de la Corte en F.A.L.

Por lo demás, resta aclarar que los protocolos que se dicten deberán ser acordes (en el sentido de que no pueden fijar más requisitos) con los lineamientos fijados por la Corte en el caso F.A.L., de lo contrario implicarían negación del derecho y, por lo tanto, serían inválidos.

\section{VI.7. Obligación de realizar campañas de información y asesoramiento}

La Corte exhorta a las autoridades de las distintas jurisdicciones a realizar "campañas de información pública, con especial foco en los sectores vulnerables, que hagan conocer los derechos que asisten a las víctimas de violación”. Asimismo establece cuáles deberán ser las acciones que lleven a cabo "las autoridades sanitarias, policiales, educativas y de cualquier otra índole" cuando tomen conocimiento de situaciones de abuso sexual. Estas deberán ser capacitadas. Advierte así la Corte que la falta de acceso a la información unida a la falta o insuficiencia de capacitación de los operadores es lo que impide en muchos casos acceder a un aborto en condiciones adecuadas. Las líneas de capacitación deberían estar dirigidas por un lado a los operadores jurídicos (jueces, defensores, fiscales, y demás personas que trabajan en estos ámbitos y que son quienes en muchos casos reciben la declaración: auxiliares de la justicia, policía, entre otros.); asimismo, a médicos y otros operadores de la salud, como enfermeros e incluso al personal administrativo. 
VII. LA SENTENCIA DE LA CORTE EN EL CASO FAL Y LAS AUTONOMÍAS PROVINCIALES: PUEDEN LOS GOBERNADORES LLAMAR A DESCONOCER EL "DERECHO FEDERAL" CON jerarquía CONSTitucional. El artículo 128 de la Constitución Nacional.

El impacto del Derecho Internacional de los Derechos Humanos

Es importante volver la mirada sobre la cuestión que la Corte está discutiendo y resolviendo en el caso F.A.L. Se trata del alcance de la interpretación de normas de derecho federal, ${ }^{58}$ en especial, las normas del bloque de constitucionalidad de las que surgen los dos derechos en conflicto que se encuentran en la base de los abortos permitidos: el derecho a la continuación de la existencia intrauterina del feto y el derecho a la autonomía y a la dignidad de las mujeres, ambos enunciados en varios instrumentos internacionales con jerarquía constitucional.

Los argumentos que la Corte utiliza para sostener la interpretación amplia del art. 86 inc. $2^{\circ}$ C.P. devienen con claridad del bloque de constitucionalidad, en este punto el fallo presenta una gran riqueza argumentativa para reiterar que la reforma de 1994 requiere replantear los lugares desde los que "tradicionalmente" se pensaron la distribución de competencias entre Estado Nacional (Federal) y provincias, en este caso, respecto de la interpretación del derecho en general. El fallo es interesante además si se lo ve desde una perspectiva argumentativa. La sentencia otorga argumentos acerca de por qué la interpretación amplia del artículo 86 inciso $2^{\circ}$ es "mejor" que la restrictiva. Para justificarlo ofrece razones de peso constitucional. Así no se trata simplemente de seguir el fallo de la Corte porque lo emitió el tribunal que es cabeza del Poder Judicial de la Nación. La legitimidad del fallo y su vinculatoriedad para las autoridades de Provincia deviene de sus razones. En este sentido los protocolos que la Corte llama a dictar a las Provincias ${ }^{59}$ no pueden ser utilizados como excusas para desconocer el derecho federal (bloque de constitucionalidad en juego y vinculante para las Provincias, argumento del art. 75 inc. 22 en relación con el art. 31 de la Const. Nac.). Así, los protocolos que impliquen interpretaciones más restrictivas, es decir, que no recepten la interpretación amplia de la Corte en F.A.L., son incompatibles con el bloque de constitucionalidad. ${ }^{60}$

\footnotetext{
58 V. Dulitzky (2006), Gutiérrez Colantuono (2007), Clérico (2010b).

${ }^{59}$ Hasta ahora las normas reglamentarias de la Provincia de Chubut y de Santa Fe son compatibles con la interpretación amplia del art. 86 inc. $2^{\circ}$ del CP.

${ }^{60}$ V. este argumento en: Bergallo (2012).
} 
El impacto del fallo fue inmediato en términos de "federalismo" y desde la perspectiva de una supuesta defensa de la autonomía provincial pero olvidando que los gobernadores son "agentes naturales del gobierno federal para hacer cumplir la Constitución y las leyes de la Nación" (art. 128 Const. Nac.). ${ }^{61}$ A pocos días de publicada la sentencia, el Gobernador de Salta dicta el decreto 1170/12 en el que instruye a los ministros de Salud Pública y de Derechos Humanos de la Provincia para que de forma inmediata elaboren las guías de procedimiento necesarias para la asistencia integral de toda víctima de violencia sexual y la concreta atención de los abortos no punibles. Sin embargo, agrega un requisito desconociendo "las razones" del fallo de la Corte en F.A.L. De acuerdo con el decreto, si no media denuncia penal voluntaria, sería un requisito para acceder a la interrupción legal del embarazo en Salta que la declaración jurada, en la que queda asentada que la mujer fue violada, fuese realizada en sede judicial con la asistencia del Ministerio Público. En sus considerandos el Gobernador dice que "debe puntualizarse, en primer lugar, que los fallos judiciales en el sistema constitucional de la República, sólo tienen efectos obligatorios para el caso concreto. De allí, entonces, que la exhortación formulada por el Tribunal constituye una recomendación y, como tal, no tiene fuerza imperativa para las autoridades provinciales, menos aún en cuanto establece normas procedimentales, v.g., la declaración jurada, prevista como medio de acreditación del delito". ${ }^{62}$ Sin embargo, en ninguna parte del Decreto se hace cargo de los argumentos referidos a los derechos de las mujeres violadas desarrollados por la Corte en su fallo. En clave argumentativa, si las autoridades provinciales al momento de regular la atención agregan algún requisito deben justificar que es para mejorar la posición de las mujeres que han sido violadas. Como sostiene Agustina Ramón Michel, "si no lo hace, es un requisito irrazonable y en la medida que afecta los derechos a la salud y a la privacidad, y puede frustrarlos, deviene inconstitucional". ${ }^{63}$ Este es el caso del Decreto No 1170/2012 de Salta cuando agrega un requisito para obstaculizar los abortos no punibles.

Tal vez el fallo de la Corte es en algún punto criticable. El diagnóstico nos dice que varias provincias, en forma más o menos camuflada, presentan fuertes resistencias para aplicar normas federales o nacionales sobre salud

${ }^{61}$ V. Gelli (2005:1038).

${ }^{62}$ Considerando del Decreto 1170/12 emitido por el Gobernador de Salta.

${ }^{63}$ Página 12, 23 de marzo de 2012, pág. 2.; v. asimismo Ramón Michel (2011). 
sexual. Por ello, es fundamental el papel que el Estado nacional, a través de sus diversas reparticiones (Ministerios), y los órganos federales que reúnen a todas las provincias (léase, por ejemplo, COFESA), actúen a favor del monitoreo e implementación de la interpretación amplia del artículo 86 inc. $2^{\circ}$ en el sentido indicado por la Corte en el caso F.A.L. En este punto la sentencia de la Corte se queda corta, pues sólo llama a las Provincias pero se olvida de recordarle al Estado nacional sus obligaciones de control y seguimiento en la materia. ${ }^{64}$

VIII. El CONFLICTO DE DERECHOS MÁS ALLÁ DEL SUPUESTO DEL INCISO 20 DEL artículo 86 del Código Penal. Proyecciones

La Corte deja en claro que detrás del art. 86 inc. $2^{\circ}$ no se encuentra sólo el derecho a la vida de la persona por nacer, como pretende sostener el Asesor Tutelar de Chubut, sino que también se trata de la protección de los derechos de las mujeres. Esto surge también de la lectura del voto de la jueza Argibay que incluso habla de "ponderación" y de "conflicto" de intereses. Esto nos lleva a interpretar que existe un conflicto entre derechos. Veamos.

\section{VIII.1. El derecho a la vida ¿regla y/o principio?}

Debemos distinguir cuando un derecho fundamental actúa como regla y como principio. En este sentido, una norma es regla cuando tiene un contenido determinado para decidir el caso. ${ }^{65}$ Esto ocurre cuando en la norma aparece determinada la conducta que está ordenada, prohibida o permitida en forma definitiva. Las reglas contienen, en este caso, una prohibición definitiva, esto quiere decir, que en el contenido de las reglas ya se han tenido en cuenta las razones que podrían haber jugado en contra de lo ordenado por el derecho humano en cuestión, y por lo tanto, ya es un deber definitivo (esto quiere decir que no admite ponderación alguna), que debe ser aplicado mediante la subsunción. En cambio los principios admiten la ponderación, pues "ordenan que algo debe

\footnotetext{
${ }^{64}$ V. Comunicación Conjunta para Examen Periódico Universal Argentina, Sesión 14, 2012: "Los derechos sexuales y los derechos reproductivos", disponible en: http://www.adc.org.ar/sw_contenido.php?id=870: según el cual algunas organizaciones requirieron al

Ministro de Salud que se manifestara sobre el fallo y que convocara una reunión del Consejo Federal de Salud (COFESA) para acordar con los ministros de salud provinciales la atención de abortos no punible. El Ministro de Salud no habría respondido aún a este pedido (por lo menos hasta el 21/4/2012).

${ }^{65}$ AleXy (1986).
} 
ser realizado en la mayor medida posible, teniendo en cuenta las posibilidades jurídicas y fácticas" ${ }^{66}$ Por lo tanto, no contienen mandatos definitivos (como las reglas) sino prima facie. Sostiene Alexy que "los principios carecen de contenido de determinación con respecto a los principios contrapuestos y las posibilidades fácticas". ${ }^{67} \mathrm{Y}$ entiende así que los principios son mandatos de optimización. Así, los casos de conflictos de este derecho con otros derechos fundamentales deberán resolverse mediante la ponderación, teniendo en cuenta el peso de los principios en pugna. ${ }^{68}$

Por ejemplo, podemos sostener que la jurisprudencia de la Corte IDH se deja reconstruir de tal manera que algunos de los derechos de la $\mathrm{CADH}$ son interpretados como principios y otros como reglas. En el caso Kimel la Corte IDH claramente interpreta el conflicto entre el derecho a la libertad de expresión de un periodista y al derecho a la honra de un juez como un conflicto entre principios; por ello aplica el examen de proporcionalidad para la resolución del conflicto a favor de la libertad de expresión de Kimel como ejercicio del derecho de crítica bajo consideración de las circunstancias del caso. ${ }^{69}$ Sin embargo, por ejemplo, cuando se trata de la protección del derecho a la integridad física y psíquica (art. $4 \mathrm{CADH}$ ) frente a la tortura, ese derecho es regla y no admite consideraciones de otros principios que admitan tortura alguna. La tortura está prohibida y en forma definitiva.

La protección de la existencia intrauterina puede entrar en conflicto con el derecho a la autonomía de las mujeres, esta es la implicancia, según vimos, del agregado "en general" del art. 4 de la CADH. Se trata de un conflicto de derechos en su carácter de principios. ${ }^{70}$ En el caso F.A.L., la jueza Argibay en su

\footnotetext{
${ }^{66}$ Alexy (2010:20).

${ }^{67}$ Alexy (1986).

68 "La solución de la colisión consiste más bien en que, teniendo en cuenta las circunstancias del caso se establece entre los principios una relación de precedencia condicionada. La determinación de la relación de precedencia condicionada consiste en que, tomando en cuenta el caso, se indican las condiciones bajo las cuales un principio precede al otro'. Bajo otras condiciones, la cuestión de la precedencia puede ser solucionada inversamente", AlEXY (1986).

${ }^{69}$ V. reconstrucción del caso en este sentido en: Clérico (2010c), Clérico (2009).

${ }^{70}$ Sobre la estructura del examen de proporcionalidad para la resolución de este conflicto, v. AleXY, Robert. Derechos sociales y ponderación. Madrid: Fundación Coloquio Jurídico Europeo, 2007; RonCONI, L., La aplicación del examen de proporcionalidad para determinar las obligaciones estatales de prestación: ¿Debe el Estado satisfacer los tratamientos de reproducción asistida?, en BEADE/ ClérICO (eds.), "Desafíos a la Ponderación”, Universidad del Externado, Bogotá, Colombia, 2011.
} 
voto deja en claro que "se está en presencia de un severo conflicto de intereses": derecho a la vida del feto frente el derecho a la autonomía de la mujer que ha sido violada. La jueza sostiene que en este conflicto ya existió una "ponderación” por parte del legislador y no se alegan argumentos para dejarla de lado. Reconoce que existen circunstancias excepcionales donde frente a una tensión entre dos bienes jurídicos el propio legislador permite afectar uno de ellos para salvaguardar al otro.

Así, el legislador dejó sentado que el derecho de las mujeres violadas prevalece frente al derecho a la vida de la persona por nacer. La interpretación restrictiva del art. 86 inc. $2^{\circ}$ implica no tomar en serio los derechos de las mujeres que han sido violadas, aniquilándolos en forma completa.

Esta postura resulta muy enriquecedora a la hora de interpretar los otros supuestos que regula el art. 86, ya que deja en claro que la existencia intrauterina del feto no tiene una prevalencia incondicionada y que podrá ceder en forma justificada en el contexto de una ponderación realizada por los legisladores o, en su caso, por la Corte (tal como lo realizó en T.S.), cuando se den determinadas circunstancias y razones de peso. Esto nos lleva al punto siguiente.

\section{VIII.2. El impacto de las normas de máxima jerarquía para interpretar las normas de derecho común}

La Corte en F.A.L. utiliza el bloque de constitucionalidad para interpretar el alcance de normas de derecho común. Para justificar la tesis de la interpretación amplia del art. 86 inc. $2^{\circ}$ ofrece razones de peso constitucional y convencional. Esta es una valiosa pauta de interpretación que debería echar la mejor luz a la interpretación del concepto "salud" del inciso $1^{\circ}$ del art. 86 del CP.

A primera vista, la principal crítica que podríamos realizar respecto de este fallo es que la Corte no resuelve el conflicto de derechos más allá de otros casos que no sean embarazos que provienen de una violación. Esto es la Corte nada dice de los otros supuestos del art. 86 inc. $1^{\circ}$ C.P. que también presentan graves problemas a la hora de hacer efectivo el derecho. Nos referimos por ejemplo a la posibilidad de que se realice un aborto en caso de que esté en riesgo la salud de la mujer. ${ }^{71}$ En principio "la interrupción del embarazo está justificada

\footnotetext{
${ }^{71}$ Aquí también se identifican prácticas de obstaculización de acceso a los abortos permitidos, al respecto en la Comunicación Conjunta para Examen Periódico Universal Argentina, Sesión 14, 2012: "Los derechos sexuales y los derechos reproductivos", op. cit., se identifican los siguientes casos que resultan paradigmáticos en clave de obstaculización. Por ejemplo, el caso de Ana María Acevedo, una joven de 20
} 
por el ejercicio legítimo del derecho de la mujer a la salud en el caso de que la continuación del embarazo ponga en peligro la vida o la salud de la madre. ${ }^{72}$ Sin embargo, una interpretación más detenida del caso de la Corte en F.A.L., permite derivar que para interpretar normas de derecho común hay que utilizar las normas del bloque de constitucionalidad. Entonces si tenemos que interpretar qué significa "salud", debemos recurrir, por ejemplo, a la caracterización del art. 13 del PIDESC, que la define como integridad fisica y psíquica, punto que la Corte ya había advertido en el fallo T.S referido en el segundo apartado de este trabajo. Asimismo debemos traer a colación el concepto de salud que brinda la OMS, según el cual, es el "estado de completo bienestar físico, mental y social y no solamente la ausencia de enfermedad". De esta manera, podemos sostener que una interpretación que tome en cuenta la norma del art. 86 inc. $1^{\circ}$ en el contexto del ordenamiento jurídico en la que está inserta (argumento de coherencia), permite el aborto en caso de que el embarazo ponga en riesgo la salud física y también psíquica de la mujer. ${ }^{73}$ Sin embargo, la interpretación restrictiva nos habla de que esto funciona en la práctica sólo en caso de riesgo para la salud física de la mujer, y ni aun así, en muchos casos. ${ }^{74}$ Por el contrario, si se siguen las razones de la Corte en F.A.L. se impone una interpretación amplia del art. 86 inc. $1^{\circ}$ C.P.

\section{CONSIDERACIONES FINALES}

Como ya lo hemos sostenido a lo largo del trabajo, sostenemos que el fallo es convincente en su argumentación cuando justifica una interpretación amplia

\footnotetext{
años, del norte de Santa Fe, que en 2007, "teniendo cáncer y estando embarazada, murió por la negativa de los médicos tanto a realizarle el aborto terapéutico que solicitó, como a brindarle tratamiento para el cáncer, argumentando que el tratamiento era incompatible con el embarazo". O el de "una mujer en Entre Ríos, quien por padecer una cardiopatía severa, que implicaba un embarazo de alto riesgo para su vida, solicitó un aborto no punible que le fue negado por los médicos. Luego de cuatro meses de internación en un hospital, alejada de su familia, llegó a dar a luz, aunque, como consecuencia, sufrió un accidente cerebrovascular que la ha dejado paralizada de por vida".

72 Clérico (2009).

${ }^{73}$ En este sentido, v. sentencias C-355 de 2006 y T- 636 de 2011 de la Corte Constitucional Colombiana, disponibles en http://www.corteconstitucional.gov.co/

${ }^{74}$ V. nota del Diario Página 12 "La sentencia que hizo justicia por Ana María" del 12 de mayo del 2010. En el caso que comentamos no sólo se trataba de una menor que había sido violada sino que distintos informes daban cuenta de que la niña estaba en un estado depresivo y que la continuidad del embarazo implicaba un grave riesgo para su integridad psicofísica. Sin embargo, esto no es tenido en cuenta como un argumento autónomo a la hora de decidir.
} 
del art. 86 inc. $2^{\circ}$ del CP, intentando poner fin de esta manera a los distintos padecimientos que sufren las mujeres cuando se ven en la necesidad de someterse a esta práctica. Además, el fallo fija pautas claras acerca de cuáles son las obligaciones que se derivan de este derecho, quiénes son los sujetos obligados (estado nacional y/o provincial y/o municipal), y cuáles son las condiciones que deben generarse para que estas prácticas garanticen un acceso al derecho a la salud seguro, oportuno y adecuado.

Más allá de esto, el fallo es importante en lo que se refiere a sus posibles proyecciones respecto de otros casos (por ejemplo, art. 86 inc. $1^{\circ}$ del CP y/o despenalización en general), ya que la Corte deja en claro que las normas deben ser interpretadas de forma tal que permitan la mayor realización posible del derecho de las mujeres que no pueden ser sometidas y tratadas como un medio para llevar a término un embarazo no deseado. Muchas de estas líneas argumentativas, que a nuestro entender habilitan nuevos reclamos y exigen cambios en el accionar del Estado, han sido detectadas y desarrolladas a lo largo del análisis del fallo.

\section{BibLIOGRAFíA}

Alexy, Robert (1986): Theorie der Grundrechte (Frankfurt am Main, Suhrkamp).

AleXY Robert (2007): Derechos sociales y ponderación. Madrid: Fundación Coloquio Jurídico Europeo.

AleXY, Robert, (2010): La construcción de los derechos fundamentales, Ed. Ad Hoc, Buenos Aires.

Alegre, Marcelo (2009): "Opresión a conciencia: La objeción de conciencia en la esfera de la salud sexual y reproductiva" en Derecho y Sexualidades. Seminario en Latinoamérica de Teoría Constitucional y Política, SELA, Ed. Librarías, Buenos Aires.

Bergallo, Paola (2012): Las nuevas responsabilidades, Página 12, Buenos Aires, 23/3/2012.

BiANCHI, Alberto (2012): “Una avance preocupante en la legalización del aborto” en, La Ley, Buenos Aires, 21/03/2012.

Clérico, Laura (2009): El examen de proporcionalidad en el derecho constitucional. Buenos Aires: EUDEBA.

Clérico, Laura (2009) "Los derechos no enumerados. Comentario al art. 33 de la Constitución Nacional" en SABSAY/Manili (coord.) Constitución de la 
Nación Argentina y normas complementarias. Análisis doctrinal y jurisprudencial. Buenos Aires: Hammurabi.

Clérico, Laura (2010a): "La jurisprudencia de la Corte sobre medicina prepaga en el contexto de un sistema de salud con fronteras híbridas", en: Suplemento Jurisprudencia Argentina, 27/10/2010.

Clérico, Laura (2010b): “¿El argumento del federalismo vs. el argumento de igualdad? El derecho a la salud de las personas con discapacidad", Revista Jurídica de Palermo, Año 11, No 1-octubre de 2010, pp. 93-118, (también disponible en: www.palermo.edu/derecho/revista_juridica/pub_a11n1. html).

Clérico, Laura (2010c): Hacia un modelo de la ponderación orientado por reglas para la solución de conflictos entre derechos fundamentales. "Teoría y práctica del derecho constitucional”. Quito: Ministerio de Justicia y Derechos Humanos, Ecuador, pp. 253-297 (también disponible en: http:// www.minjusticia-ddhh.gov.ec).

Gelli, María Angélica (2005): Constitución de la Nación Argentina, Ed. La Ley, Buenos Aires.

Morlachetti, Alejandro (2011): "Adolescencia y juventud: sus derechos sexuales y reproductivos", Suplemento de Jurisprudencia Argentina, $1 / 6 / 2011$.

DulitzKY, Ariel (2006): "Federalismo y derechos humanos: el caso de la Convención Americana sobre Derechos Humanos y la República Argentina”, Anuario Mexicano de Derecho Internacional, No 6.

Gutiérrez Colantuono, Pablo A (2007): Derechos económicos, sociales y culturales, omisiones estatales y nuevos contornos del federalismo, JA 2007 III 1187.

Nino, Carlos (1989): Ética y derechos humanos un ensayo de fundamentación. Buenos Aires, Astrea.

Pecheny, Mario y de la Dehesa, Rafael (2010): "Sexualidades y políticas en América Latina: el matrimonio igualitario en contexto" en: CLÉRICO, Laura y ALDAO, Martín (coords.) Matrimonio igualitario. Perspectivas sociológicas, políticas y jurídicas (Buenos Aires, EUDEBA).

PinTo, Mónica (2004): "El principio pro homine. Criterios de hermenéutica y pautas para la regulación de los derechos humanos" en Abregu, Martín/ Courtis, Christian (Comp.) La aplicación de los tratados sobre derechos humanos por los tribunales locales, Buenos Aires: del Puerto. 
Ramón Michel, Agustina (2011): "El fenómeno de inaccesibilidad al aborto no punible”, en: Paola Bergallo (comp.), Aborto y justicia reproductiva, Editores del Puerto, Buenos Aires.

Ramos Silvina, Bergallo Paola, Romero Mariana y Arias Feijoó Jimena (2009) "El acceso al aborto permitido por la ley: un tema pendiente de la política de Derechos Humanos en la Argentina"; en Centro de Estudios legales y Sociales (CELS): Derechos Humanos en Argentina, Informe 2009, Siglo Veintiuno Editores, Buenos Aires.

RodrígueZ, Marcela (2007): "Entre la justicia real y la justicia formal; la discriminación por género en la jurisprudencia de la Corte Suprema de Justicia de la Nación" en: Alegre/Gargarella (coord.), El derecho a la igualdad. Aportes para un constitucionalismo igualitario, LexisNexis, Buenos Aires.

RonCONI, Liliana (2011): La aplicación del examen de proporcionalidad para determinar las obligaciones estatales de prestación: ¿Debe el Estado satisfacer los tratamientos de reproducción asistida?, en BEADE/ ClérICO (eds.), "Desafíos a la Ponderación”, Universidad del Externado, Bogotá, Colombia.

Siverino Bavio, Paula (2006): Derechos Humanos y Ligadura de Trompas. Comentario a la ley 26.130, La Ley 2006- F, p. 1254.

\section{JURISPRUDENCIA}

Corte Suprema de Justicia de la Nación Argentina (disponibles en: www.csjn.gov.ar)

"F., A. L. s/ medida autosatisfactiva”, CSJN, 13/03/2012.

"Núñez de Zanetti", CSJN, 9/9/ 2008.

"Mujeres por la vida c. Ministerio de Salud y Acción Social", CSJN, 31/10/2006. "Y.,G.C. c. Nuevo Hospital El Milagro y otra", CSJN, 06/06/2006.

"Asoc. Civil Portal de Belén c. Ministerio de Salud y Acción Social", CSJN05/03/2002.

“T., S. c. Gobierno de la Ciudad de Buenos Aires”, CSJN, 11/01/2001.

\section{Corte Constitucional Colombiana}

(disponibles en http://www.corteconstitucional.gov.co/)

Sentencia C-355 de 2006

Sentencia T-209 de 2008

Sentencia T- 636 de 2011 


\section{Corte Interamericana de Derechos Humanos}

Caso Fernández Ortega y Otros vs. México, Sentencia de 15 de mayo de 2011.

Suprema Corte de los Estados Unidos

"Roe vs. Wade", US 113, 93 (1973).

"Planned Parenthood of Southeastern Pennsylvania v. Casey", U.S. 833 (1992).

\section{INFORMES Y RECOMENDACIONES}

Informe de la CIDH sobre Guatemala 2001, OEA/Ser.//V/II.111, doc. 21 rev, de 6 de abril de 2001.

Informe de la CIDH No 20/07, Solución Amistosa, Petición 161-02, Paulina del Carmen Ramírez Jacinto, México, 9/3/2007.

Recomendación general No 24 s/el art. 12 de la Convención sobre la eliminación de todas las formas de discriminación contra la mujer.

Comité de Derechos Humanos, Observaciones Finales: Ecuador, 18/08/1998, Chile, 30/03/1999, Perú, 15/11/2000.

Resolución 23/81 de la Comisión Interamericana de Derechos Humanos ("Baby Boy").

Informe de la Comisión IDH Acceso a la Justicia para las mujeres víctimas de violencia en las Américas, OEA/Ser.L/V/II. Doc. 68, 20 enero 2007.

Informe de la CIDH, Acceso a Servicios de Salud Materna desde una Perspectiva de Derechos Humanos, OEA/Ser.L/V/II. Doc. 69, 7 de junio de 2010, (disponible en: www.cidh.oas.org/pdf\%20files/mujeresaccesoinformacionmateriareproductiva.pdf).

Informe de la CIDH, Acceso a la Información en Materia Reproductiva desde una Perspectiva de Derechos Humanos OEA/Ser.L/V/II. Doc. 6122 noviembre 2011.

\section{DOCUMENTOS}

Informe de un grupo de ONG (Cedes, Insgenar, Cladem, Ela, Foro por los Derechos Reproductivos, Católicas por el Derecho a Decidir, Cels, Foco, Feim y ADC) presentado en abril de 2012 ante la ONU: Comunicación Conjunta para Examen Periódico Universal Argentina, Sesión 14, 2012: 
"Los derechos sexuales y los derechos reproductivos", (fecha de consulta, marzo 2012) Disponible en: www.adc.org.ar/sw_contenido.php?id=870

Mario S./ Pantelides E. "Estimación de la magnitud del aborto inducido en Argentina” en: Nota de población No 87, CEPAL, 2009, (fecha de consulta, marzo 2012) Disponible en: http://www.eclac.cl/publicaciones/xml/1/36501/ $\operatorname{lcg} 2405-P \_4 . p d f$

Comunicación Conjunta para Examen Periódico Universal Argentina, Sesión 14, 2012: "Los derechos sexuales y los derechos reproductivos", (fecha de consulta, marzo 2012) Disponible en: http://www.adc.org.ar/sw_contenido. php?id=870:

\section{NOTAS PERIODÍSTICAS}

Notas del Diario Página 12:

"Ni con el aval del tribunal máximo" del 22 de septiembre del 2007,

"Una intervención ante las demoras" del 31 de enero del 2009,

"Un derecho con jurisdicción" del 7 de febrero de 2009,

"Un derecho que llegó con demoras" del 10 de abril del 2010,

"La sentencia que hizo justicia por Ana María" del 12 de mayo del 2010,

"Una situación embarazosa", 23 de marzo de 2012. 
